\title{
Comparison of thin section computed tomography with bronchography for identifying bronchiectatic segments in patients with chronic sputum production
}

\author{
Neil C Munro, Julie C Cooke, David C Currie, Basil Strickland, Peter J Cole
}

\begin{abstract}
Computed tomography is widely used in the investigation of patients in whom bronchiectasis is suspected, despite considerable variation in its reported sensitivity and specificity. The findings with $3 \mathrm{~mm}$ high resolution computed tomography were compared at segmental level with bronchography by two radiologists independently in 27 patients (aged 20-67 years) undergoing investigation of chronic sputum production. Fifteen patients were found to have bronchiectasis by both investigations. Five were identified by computed tomography alone, including two in whom disease was revealed in segments underfilled at bronchography. The sensitivity of computed tomography compared with bronchography in the diagnosis of bronchiectasis at segmental level was $84 \%$ and the specificity $82 \%$. The predictive value of computed tomography in the diagnosis of bronchiectasis was $38 \%$ overall, but increased to $75 \%$ when only those segmental bronchi moderately or severely dilated on the computed tomography scan were considered. There was no relation between the degree of bronchial wall thickening on the computed tomogram and the diagnosis of bronchiectasis by bronchography. Bronchography may be avoided in patients being considered for surgical resection of their bronchiectasis in whom computed tomography shows diffuse disease.
\end{abstract}

Host Defence Unit, Department of Thoracic Medicine, National Heart and Lung Institute,

London

N C Munro

D C Currie

P J Cole

Department of Radiology, Brompton Hospital, London J C Cooke B Strickland

Address for reprint requests: Professor P J Cole, Host Defence Unit, Department of Thit, Medicine, National Heart Medicine, National Heart
and Lung Institute, London and Lung I

Accepted 2 November 1989

Chronic sputum production remains a common problem in Britain despite improved treatment of pulmonary infections and more widespread immunisation against whooping cough and measles in childhood. Bronchiectasis, defined as abnormal and irreversible dilatation of one or more bronchi, ${ }^{1}$ is present in some of these patients. Assessing the extent and distribution of the bronchiectasis is important for determining the most appropriate management.

Bronchography is the definitive investigation for bronchiectasis but the investigation remains unpleasant despite the improvements bestowed by the fibreoptic bronchoscope. Computed tomography has therefore emerged as the investigation of choice in patients with suspected bronchiectasis, despite widely varying reports of its sensitivity and specificity by comparison with bronchography. ${ }^{2-8}$ The published accounts are based on widely varying groups of patients, different computed tomography slice widths, and different assessments of the results at the level of whole lungs, lobes, and segments.

Three millimetre section computed tomography provides better clinical information than the $10 \mathrm{~mm}$ sections we studied previously. ${ }^{7}$ We report the sensitivity and specificity of $3 \mathrm{~mm}$ section computed tomography of the lung compared with bronchography in the diagnosis of bronchiectasis at segmental level.

\section{Methods \\ PATIENTS}

We studied 27 patients with cough and sputum production who underwent both fibreoptic bronchography and computed tomography at the Brompton Hospital during 1987. The investigations were requested by the referring physicians as part of the patients' clinical investigations.

\section{INVESTIGATIONS}

Bronchography was performed via a fibreoptic bronchoscope with an aqueous suspension of propyliodone (Dionosil Aqueous, Glaxo), radiographic screening being used to ensure optimal bronchial filling wherever possible. Twenty six bronchograms were bilateral and one unilateral. Computed tomography was performed on an Elscint 2002 scanner with a five second scanning time and a $512 \times 512$ matrix. All patients were scanned supine in arrested full inspiration from lung apex to diaphragm in $10 \mathrm{~mm}$ increments, $3 \mathrm{~mm}$ sections being used with a wide window width and a bone algorithm. ${ }^{9}$ None of the patients had an acute exacerbation of their symptoms at the time of the study.

Bronchogram films and computed tomograms were assessed separately in random order by two experienced pulmonary radiologists working independently. Bronchograms were interpreted at segmental level and the radiologist reported whether bronchiectasis was present, the degree of bronchial dilatation (on a scale from 0 to $+++: 0=$ normal, $+=$ mild, $++=$ moderate and $+++=$ severe), whether there was loss of filling of side 
branches (stripping), presence or absence of mucus in the bronchial tree and of mucus pits, and adequacy of filling of the bronchi.

Individual pulmonary segments were identified on the computed tomogram from the anatomical division of the appropriate lobar bronchus. ${ }^{10}$ Bronchiectasis was recognised by dilated bronchi in the periphery of the lung, a linear array or cluster of cysts, air-fluid levels in distended bronchi, and bronchial wall thickening as described by Naidich et al. ${ }^{2}$ Normal bronchi have a smaller diameter than their accompanying pulmonary artery. The radiologists reported each segment for bronchiectasis, bronchial dilatation on a 0 to +++ scale (as above), bronchial wall thickening ( 0 to +++ , as above) and the presence or absence of parenchymal disease. Where there was disagreement about the presence of bronchiectasis in a segment, both radiologists independently were asked to report again on that lobe at the segmental level-without knowing the identity of the disputed segment or their own previous findings for that lobe. If the diagnosis for a particular segment was still disputed a consensus opinion was requested from the two radiologists reporting on the film together. If no agreement was achieved, the segment was taken to be non-bronchiectatic for the purposes of the analysis.

\section{ANALYSIS}

Bronchography was chosen as the investigation against which computed tomography was judged. We determined the sensitivity and specificity of computed tomography at a segmental level. Sensitivity (\%) was calculated as
No of bronchiectatic segments on both computed tomogram and bronchogram

No of bronchiectatic segments on $\times 100$ bronchogram

Specificity (\%) was calculated as

No of non-bronchiectatic segments on both computed tomogram and bronchogram

No of non-bronchiectatic segments on bronchogram

The predictive value ( $\%$ ) of computed tomography was calculated as

No of bronchiectatic segments on both computed tomogram and bronchogram

No of bronchiectatic segments on $\times 100$. computed tomogram

Statistical comparisons were made with the $\chi^{2}$ test.

\section{Results}

The clinical characteristics of the 27 patients are shown in table 1. Fifteen patients had bronchiectasis according to bronchography, all of whom had bronchiectasis on the computed tomography scan. Five patients were considered to have bronchiectasis on the scan only; in two of these it was in one or more segments that had been inadequately filled for bronchography. Seven patients had no evidence of bronchiectasis on either investigation.

The 471 segments that were filled adequately at bronchography are analysed separately from the 27 segments that were underfilled.

The radiologists, reporting independently, agreed on the bronchographic findings in 418

Table 1 Clinical characteristics of the 27 patients with cough and sputum production investigated by bronchography $(\mathrm{Bg})$ and computed tomography (CT)

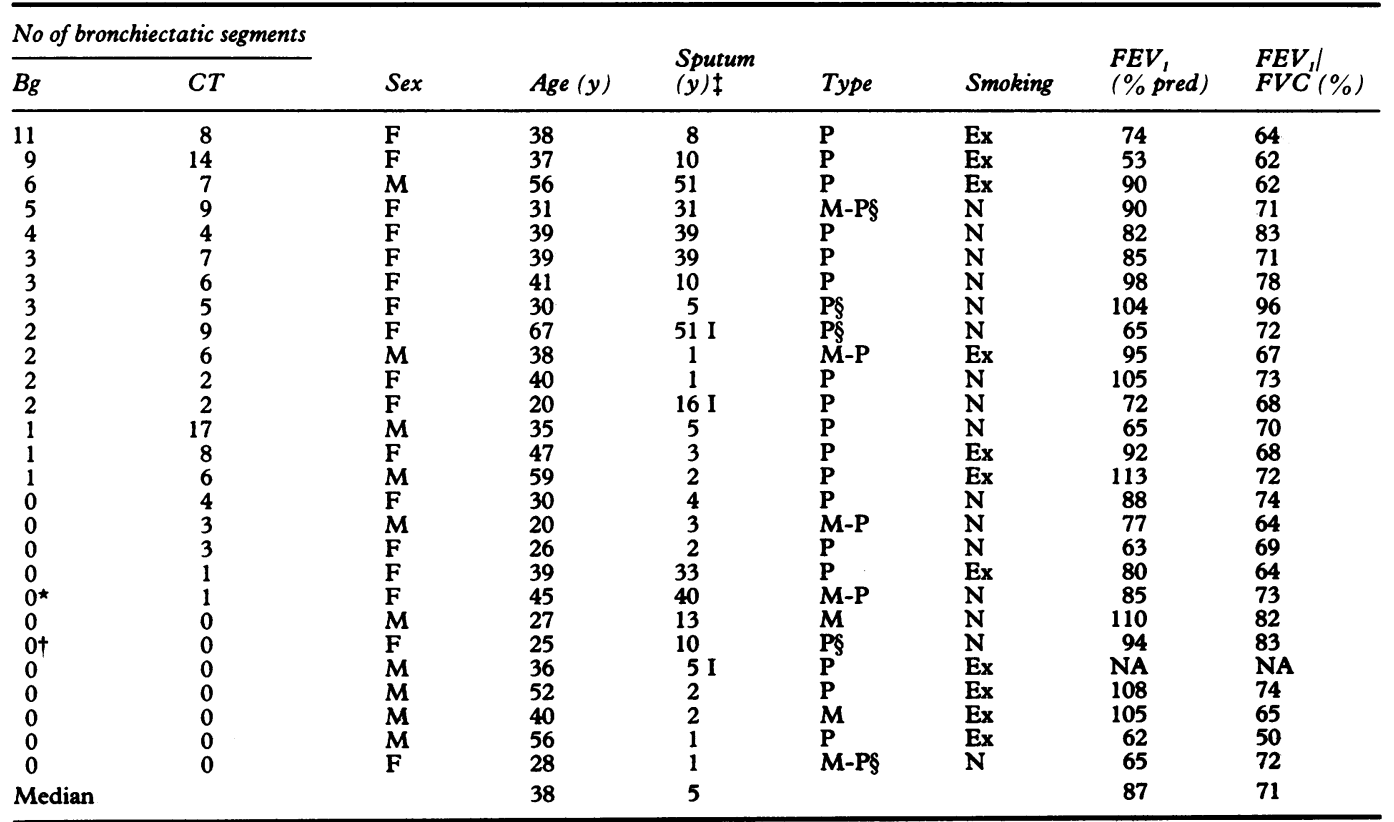

I-intermittent; $\mathrm{M}$-mucoid; $\mathrm{M}-\mathrm{P}$-mucopurulent; $\mathrm{P}$ - purulent; NA-not available; $\mathrm{N}$-never; Ex-ex-smoker. ^Five segments previously resected for bronchiectasis.

t Left sided bronchogram only.

YYears of continuous sputum production unless marked $I=$ intermittent.

$\$$ History of haemoptysis. 
Table 2 Computed tomography versus bronchography in the diagnosis of bronchiectasis in 471 segments

\begin{tabular}{lll}
\hline & \multicolumn{2}{c}{\begin{tabular}{c} 
Computed tomography \\
\cline { 2 - 3 } Bo of segments No of segments \\
bronchiectatic not bronchiectatic
\end{tabular}} \\
\hline Bronchography & $\begin{array}{l}\text { No of } \\
\text { segments } \\
\text { bronchi- } \\
\text { ectatic }\end{array}$ & $\begin{array}{l}\text { No of } \\
\text { segments } \\
\text { not } \\
\text { bronchi- } \\
\text { ectatic }\end{array}$ \\
\hline
\end{tabular}

of the 471 segments. After they had conferred about the remaining segments, 13 were classified as bronchiectatic and 39 as non-bronchiectatic. The radiologists agreed about 423 of the 471 segments on the computed tomograms. After discussion of the remaining segments 24 were considered bronchiectatic and 23 non-
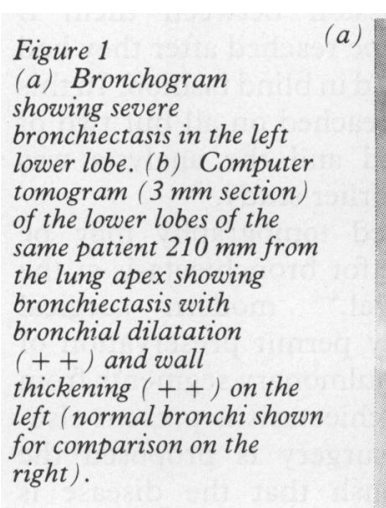

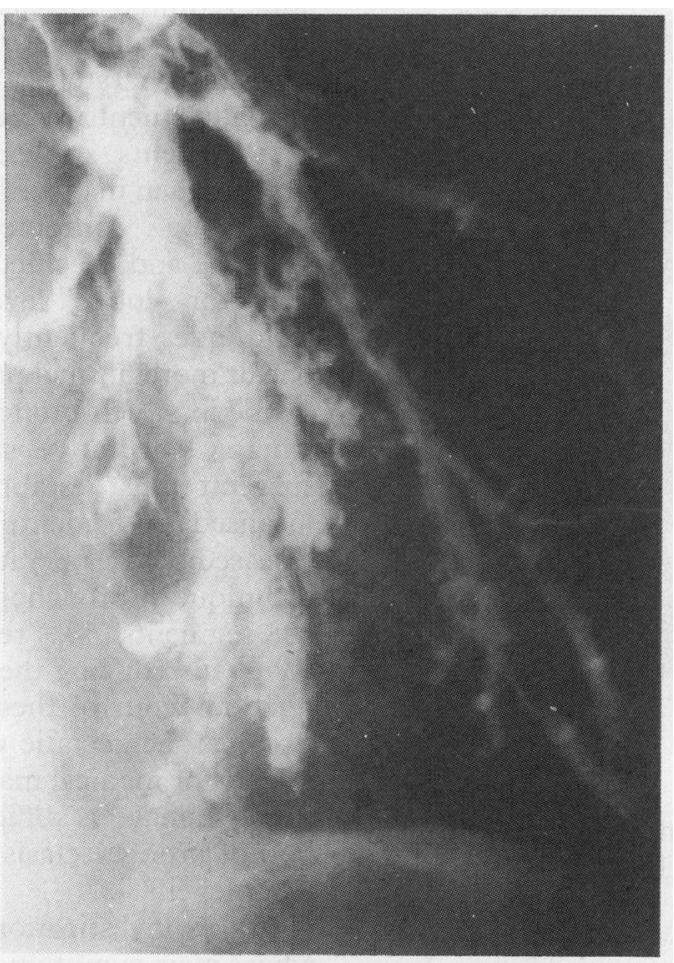

(b)

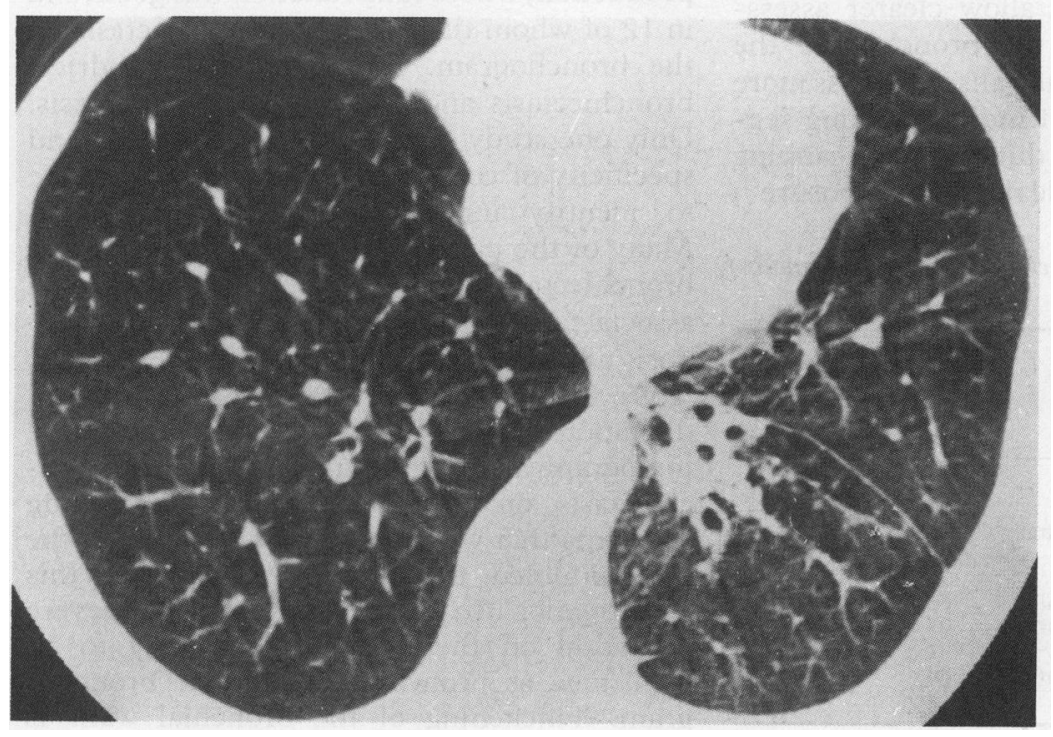

bronchiectatic. No agreement was reached on one segment with bronchography and one with computed tomography; both were regarded as non-bronchiectatic for the purposes of analysis. The final result is summarised in table 2. Bronchiectasis was diagnosed by bronchography in 55 segments, of which 46 were reported as bronchiectatic on the computed tomography scan (fig 1). The sensitivity of computed tomography was therefore $84 \%$. Of the nine segments with bronchiectasis on the bronchogram alone, six were interpreted as normal on the scan, two as showing bronchial wall thickening, and one as showing only parenchymal changes. No bronchographic evidence of bronchiectasis was found in $\mathbf{4 1 6}$ segments, of which 340 were negative for bronchiectasis by both investigations. The specificity of computed tomography was therefore $82 \%$. Of the 76 segments that were interpreted as showing bronchiectasis by computed tomography only, 55 were normal on the bronchogram, nine (fig 2) showed mucus only (though this was not considered sufficient to hinder interpretation), and 12 had a combination of mucus, stripping, and mucus pits.

Bronchiectasis was diagnosed in $122 \mathrm{seg}-$ ments by computed tomography and in only 46 of these by bronchography, giving a predictive value of $38 \%$ for computed tomography in the diagnosis of bronchiectasis. Bronchiectasis was confirmed by bronchography in 18 of the 24 segments with moderate or severe bronchiectasis on the computed tomography scan, giving a predictive value of $75 \%$. Such segments were more likely to have been reported as bronchiectatic on the bronchogram than those that were only mildly dilated $(p<0.001)$. The wall thickness of the segments showing bronchiectasis on the scan did not increase the predictive value of computed tomography and showed no significant relation to the degree of dilatation seen on the scan.

In the 27 segments that were underfilled on the bronchogram the computed tomogram was normal in 23 and showed bronchiectasis in four.

At the lobar level computed tomography showed bronchiectasis in 23 out of 24 lobes that were bronchiectatic on bronchography (sensitivity $95 \%$ ). Ninety five lobes showed no bronchiectasis by either investigation and 126 lobes had no bronchiectasis on the bronchogram, giving a specificity of $75 \%$ for computed tomography at lobar level, and a predictive value of $43 \%$.

Only 10 segments were abnormal on both the computed tomography scan and the bronchogram without being bronchiectatic. Of the nine showing bronchial wall thickening on the scan, five had mucus on the bronchogram and four had a combination of mucus, stripping, and mucus pits. The other segment showed parenchymal changes on the scan and mucus on the bronchogram. A further eight segments showed wall thickening only on the scan, with a normal bronchogram. Nine segments on the bronchogram showed the presence of mucus only and 12 a combination of mucus, stripping, and mucus pits, all with a normal scan. 
Figure 2

(a) Bronchogram of the right upper lobe showing minor irregularity of the bronchial wall and the presence of a small amount of mucus but no evidence of bronchiectasis. The dye was introduced via a fibreoptic bronchoscope, which is seen in the right main bronchus.

(b) Computed tomogram same patient at the level of division of the upper lobe bronchus into apical, anterior, and posterior segmental bronchi on the right, $70 \mathrm{~mm}$ below the lung apex. Bronchiectasis with bronchial dilatation $(+)$ and wall thickening $(++)$ is seen on the right (arrowed). ( $3 \mathrm{~mm}$ section) from the
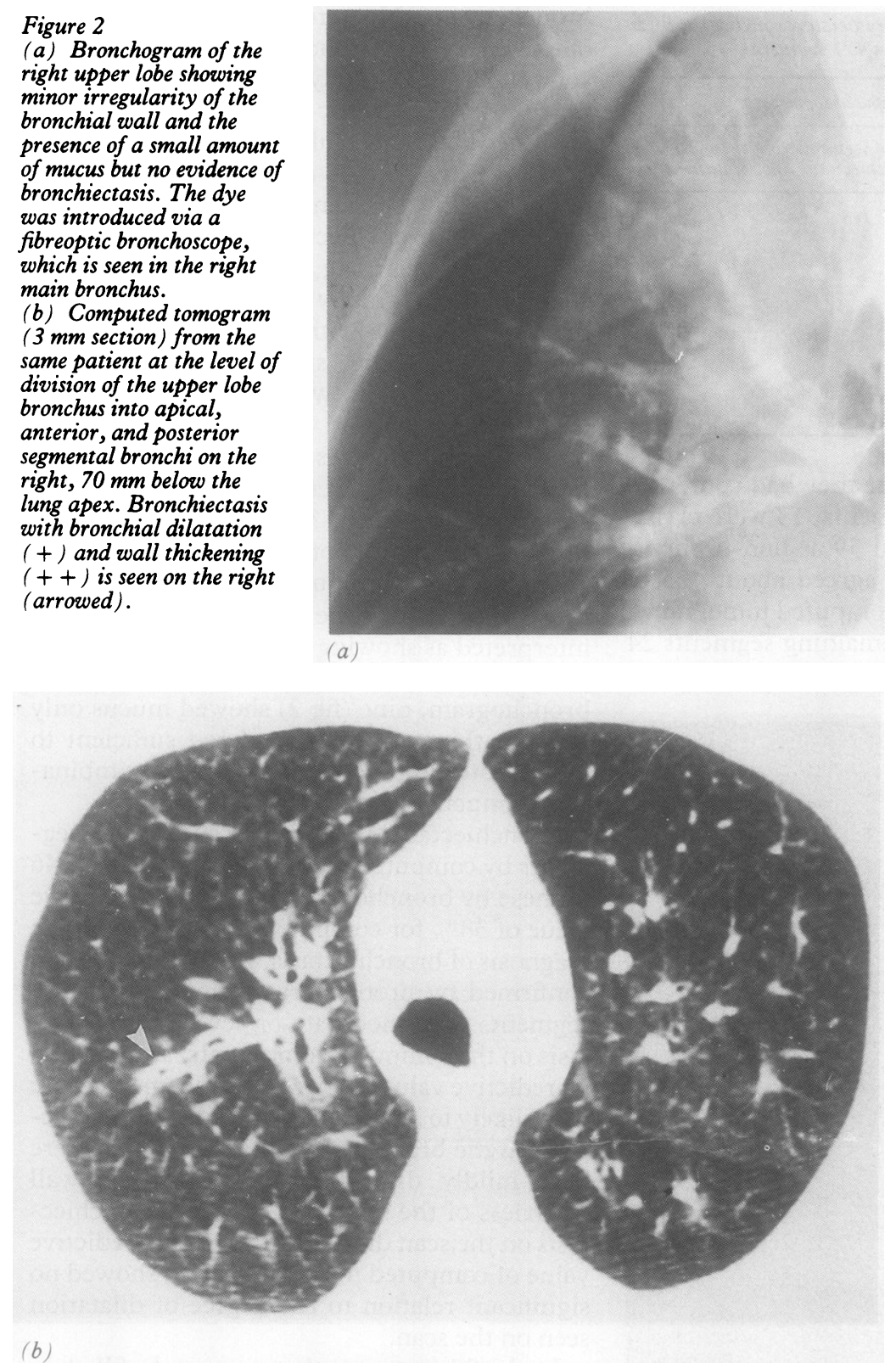

Discussion

The clinical value of computed tomography in the diagnosis of bronchiectasis is disputed despite several studies (table 3 ). The discrepancies among these studies may be explained by several factors. Thinner slices improve resolution and allow clearer assessment of the width of the bronchi and the thickness of the bronchial walls, as well as more accurate identification of individual lung segments. But contiguous thin section scanning would cause unacceptable radiation exposure ${ }^{11}$;

Table 3 Studies comparing computed tomography with bronchography in the diagnosis of bronchiectasis

\begin{tabular}{|c|c|c|c|c|c|c|}
\hline $\begin{array}{l}\text { First } \\
\text { author }\end{array}$ & $\begin{array}{l}\text { Slice } \\
\text { width } \\
(\mathrm{mm})\end{array}$ & $\begin{array}{l}\text { No } \\
\text { of } \\
\text { patients }\end{array}$ & $\begin{array}{l}\text { No of patients } \\
\text { with cystic } \\
\text { or varicose } \\
\text { disease }\end{array}$ & $\begin{array}{l}\text { Level of } \\
\text { assess- } \\
\text { ment }\end{array}$ & $\begin{array}{l}\text { Sensi- } \\
\text { tivity } \\
(\%)\end{array}$ & $\begin{array}{l}\text { Speci- } \\
\text { ficity } \\
(\%)\end{array}$ \\
\hline $\begin{array}{l}\text { Muller }{ }^{3} \\
\text { Mootoosamy }^{4}\end{array}$ & $\begin{array}{l}10 \\
10\end{array}$ & $\begin{array}{l}9 \\
8\end{array}$ & $\begin{array}{l}3 \\
4\end{array}$ & $\begin{array}{l}\text { Lung } \\
\text { Lobar } \\
\text { Segmental }\end{array}$ & $\begin{array}{r}43 \\
100 \\
81\end{array}$ & $\begin{array}{r}85 \\
100 \\
95\end{array}$ \\
\hline $\begin{array}{l}\text { Grenier } \\
\text { Philips }^{6} \\
\text { Cooke }^{7} \\
\text { Joharjy }^{8}\end{array}$ & $\begin{array}{c}1 \cdot 5 \\
8 \\
10 \\
4\end{array}$ & $\begin{array}{l}36 \\
15 \\
27 \\
20\end{array}$ & $\begin{array}{l}\text { (13/28 lungs) } \\
\text { Not stated } \\
1 \\
\text { (49/101 } \\
\text { segments) }\end{array}$ & $\begin{array}{l}\text { Lung } \\
\text { Lobar } \\
\text { Segmental } \\
\text { Segmental }\end{array}$ & $\begin{array}{l}96 \\
79 \\
66 \\
97\end{array}$ & $\begin{array}{r}94 \\
99 \\
92 \\
100\end{array}$ \\
\hline $\begin{array}{l}\text { Munro } \\
\text { (present study) }\end{array}$ & 3 & 27 & 1 & Segmental & 84 & 82 \\
\hline
\end{tabular}

scans must therefore be non-contiguous and this in turn means that some regions of the lung are not imaged. Thus with this technique we may miss localised bronchial dilatations that fall between the sections scanned. This may be more of a problem in the diagnosis of milder cylindrical disease than of more severe cystic disease. In general, studies using thin sections have shown computed tomography to have greater sensitivity, ${ }^{568}$ and this has been our experience in the current study, which used 3 $\mathrm{mm}$ sections-in contrast with our previous work on a similar group of patients with $10 \mathrm{~mm}$ sections. $^{7}$

Currie et $a l^{12}$ showed that the reporting of bronchiectasis on chest radiographs and bronchograms by radiologists is subjective, and Garland $^{13}$ has shown that the accuracy of reporting is improved when several radiologists collaborate, though this may mean some loss of sensitivity. We arranged for two radiologists to examine the films in this study and required discussion between them if agreement could not be reached after they had reported separately and in blind fashion. In this way agreement was reached on all but two of the segments studied and the analysis was simpler than in our earlier study. ${ }^{12}$

Although computed tomography may be sensitive and specific for bronchiectasis at the lung or lobar level, ${ }^{4-6}$ modern surgical techniques frequently permit preservation of one or more normal pulmonary segments from a lobe in which bronchiectasis is present elsewhere. If curative surgery is proposed the surgeon must establish that the disease is localised and identify which segments are diseased before operation. Despite attention to technique at bronchography 27 bronchi out of 498 segments $(5 \%)$ remained underfilled with contrast, reducing the sensitivity of the investigation. Four of these segments were shown to be bronchiectatic on the computed tomogram. For medical management adequate postural drainage is difficult unless the distribution of bronchiectasis is known at least at the lobar level.

In this investigation we studied 27 patients whose main symptoms were cough and sputum production, whose lung function was good, and in 12 of whom there was no bronchiectasis on the bronchogram. Fourteen had cylindrical bronchiectasis and one cystic bronchiectasis. Only one study has found the sensitivity and specificity of computed tomography adequate to identify individual diseased segments. ${ }^{8}$ Many of the patients in that study had severe bronchiectasis and severity of disease has been associated with higher sensitivity for the diagnosis of bronchiectasis. ${ }^{458}$

We found a relation between the degree of dilatation of bronchi on the computed tomography scan and the presence of bronchiectasis on the bronchogram. Excluding segments that were only mildly dilated on the scan doubled the predictive value of this investigation. In practice, moderate or severe dilatation on the scan is very likely to be confirmed as bronchiectasis on the bronchogram. Thickening of the bronchial walls is 
often seen on the scan: bronchography showed that these were not usually bronchiectatic. Similarly, bronchiectasis found on the scan but unconfirmed by bronchography was not associated with other non-specific bronchographic features of chronic bronchitis, such as mucus, loss of side branches, or mucus pits. ${ }^{12}$ Its functional and pathological significance has yet to be determined.

The sensitivity and specificity of $3 \mathrm{~mm}$ section, high resolution computed tomography permits serial examination of bronchiectatic patients without recourse to repeat bronchography. Patients being assessed for surgery whose computed tomogram shows limited disease may still require bronchography, but computed tomography will avert the need for bronchography in many patients with diffuse disease.

NCM is supported by Lilly Industries (UK). This work was supported by the Chest, Heart, and Stroke Association.
1 Reid L. Reduction of bronchial subdivision in bronchiectasis. Thorax 1950;5:233-47.

2 Naidich DP, McCauley DI, Khouri NF, Stitik FP, Siegelman SS. Computed tomography of bronchiectasis. J Comput Assist Tomogr 1983;6:437-44.

3 Muller NL, Bergin CJ, Ostrow DN, Nichols DM. Role of computed tomography in the recognition of bronchieccomputed tomography in the

4 Mootoosamy IM, Reznek RH, Osman J, Rees RSO Green M. Assessment of bronchiectasis by computed Green M. Assessment of bronchiecta

5 Grenier MD, Maurice F, Musset D, Menu Y, Nahum H. Bronchiectasis: assessment by thin-section CT. Radiology 1986;161:95-9.

6 Philips MS, Williams MP, Flower CDR. How useful is computed tomography in the diagnosis and assessment of bronchiectasis? Clin Radiol 1986;37:321-5.

7 Cooke JC, Currie DC, Morgan AD, et al. Role of computed tomography in the diagnosis of bronchiectasis. Thorax 1987;42:272-7.

8 Johariy IA, Bashi SA, Abdullah AK. Value of mediumthickness CT in the diagnosis of bronchiectasis. AJR 1987;149:1133-7.

9 Strickland B, Brennan J, Denison DM. Computed tomography in diffuse lung disease: improving the image. Clin Radiol 1986;37:335-8.

10 Naidich DP, Terry PB, Stitik FP, Siegelman SS. Computed Tomography of the Bronchi: 1. Normal Anatomy. $J$ Comput Assist Tomogr 1980;4:746-53.

11 Evans SH, Davies R, Cooke J, Anderson W. A comparison of radiation doses to the breast in computed tomographic chest examinations for two scanning protocols. Clin Radiol 1989;40:45-6.

12 Currie DC, Cooke JC, Morgan AD, et al. Interpretation of bronchograms and chest radiographs in patients with bronchograms and chest radiographs in patients with

13 Garland LH. Studies on the accuracy of diagnostic procedures. $A J R$ 1959;82:25-38. 